DOI: http://dx.doi.org/10.24093/awejtls/vol1no1.13

\title{
Investigating "Unfaithful" Translations via the Appraisal Theory: A Case Study of Public Notices
}

\author{
Hong Qian \\ The Applied Translation Studies Programme, \\ Division of Humanities \& Social Sciences \\ Beijing Normal University-Hong Kong Baptist University United International College \\ Zhuhai, China
}

\begin{abstract}
It is noticed that some English translations of Chinese public notices are "unfailthful" especially in terms of the linguistic expressions.This article attempts to investigage those English translations and compare them with the source texts via the Appraisal theory. The research questions are as follows: 1) What is the source text producer's appraisal? 2) What is the translator's appraisal? And how is the translator's appraisal reflected in the target texts? 3) What are the differences between the source text producer's appraisal and the translator's appraisal? 4) What are the possible reasons for the translator to choose his/her appraisal and produce "unfaithful" translations? In order to anwer these questions, five Chinese public notices and their English translations which were mainly collected in Hong Kong and Macao are investigated in the present study. The source and target texts are analyzed with the Appraisal theory and then compared to find out their respective appraisal. The findings show that for both Attitude and Engagement parts, the appraisal between source texts and target texts is rather different. Some possible motivations are then explored. It is believed that socio-cultural environment is one of the most important factors influencing translators' decision making in translating public notices. Besides, text types and linguistic conventions also contribute to the "unfaithful" phenomenon.
\end{abstract}

Key Words: Appraisal theory, public notices, reasons, "unfaithful” translation

Cite as: Qian, H. (2017). Investigating "Unfaithful” Translations via the Appraisal Theory: A Case Study of Public Notices. Arab World English Journal for Translation \& Literary Studies, $1(1)$.

DOI: http://dx.doi.org/10.24093/awejtls/vol1no1.13 